\title{
Mobility Patterns of the Portuguese Population during the first year of the COVID-19 Pandemic: A Longitudinal Study
}

\author{
Tiago Tamagusko ${ }^{1}$, Adelino Ferreira ${ }^{1, *}$ \\ 1 University of Coimbra, Research Center for Territory, Transports and Environment, Department of Civil \\ Engineering, 3030-788 Coimbra, Portugal \\ * Correspondence: adelino@dec.uc.pt
}

\begin{abstract}
This study analyzes the relationship between the spread of the SARS-CoV-2 virus (COVID-19) and the mobility patterns of the Portuguese population. By reducing mobility, the idea is that contacts are reduced, countering the spread of the virus in the community. As an indicator of the spread of the virus, the reproduction number $(R t)$ was used. Data from Google's Community Mobility Reports was used to evaluate changes in mobility patterns. This report uses location data from Android mobile phone users. The locations are divided into retail and recreation, grocery and pharmacy, parks, transit stations, workplaces and residential. In this year of the COVID-19 crisis in Portugal, population mobility patterns have changed over the various phases of the pandemic. At first, all mobility was affected uniformly, with the population avoiding much of the activity outside the home. In a second phase, there was some adaptation, and the areas considered to be of lower risk had less impact, emphasizing the changes in the relationship between daily life and the workplace.
\end{abstract}

Keywords: COVID-19; mobility patterns; Rt; changepoint; modeling; Portugal; Longitudinal Study

\section{Introduction}

The world has been living with SARS-CoV-2 (C OVID-19) for over a year. In Portugal, the first confirmed case was on 2 March 2020 [1]. The virus spread around the world and is considered a pandemic [2]. Since then, there has been a significant effort by the academic community to help fight Covid-19. However, there is a lack of knowledge about the impact of government measures and policies on reducing contagions. This study is a continuation of the article published on 23 November 2020 [3]. This new article intends to deepen the discussion and analyze trends one year after the first case. As a way of measuring the efficacy of actions to combat COVID-19, the effective reproduction number (Rt) was used. This value represents the average number of secondary cases per infected case at time $t[3,4]$. Consequently, an $R t$ equal to 3 means that, on average, each infected person contaminates another three people. Hence, this value must be below 1 (number of infected people decreasing with time), to control the pandemic [5].

In the first year of the pandemic, the Portuguese government adopted a series of measures to control the disease. The world started vaccination in late 2020 yet it will still take some time for most countries to achieve herd immunity at the current rate. So, at this point, the best alternatives to control the pandemic remain physical distance, frequent handwashing, and the use of personal protective equipment $[5,6]$. Based on this principle, this study investigates the influence of the mobility of the Portuguese population on the spread of COVID-19.

Portugal is now at the end of its third wave, which started right after the Christmas and New Year celebrations of 2020. In the first wave of COVID-19, in March 2020, the measures adopted managed to contain the spread of the pandemic, and we believe that this is mainly due to the quick response adopted by the government, which approved the lockdown at an early stage of the pandemic [7]. However, the first wave was followed by 
a second wave that started in September 2020. This may have been caused by the relaxation of measures in the summer, by the greater mobility of people during the summer holidays, and the feeling of relative success in controlling the pandemic's first wave. Despite the apparent success of the initial measures to combat COVID-19, the value of $R t$ persistently remained above 1 for months, which led to a slow but steady increase in the number of people infected. The prolonged period of pandemic and the inability to reduce the contagion rates created a sense of exhaustion among those responsible for fighting the pandemic directly and in the general public.

This research used exploratory data analysis to provide insights into the mobility patterns of the Portuguese people during the COVID-19 pandemic. So far, until 10 March 2021, more than 16 thousand deaths in Portugal related to cases of COVID-19 have been confirmed [8]. The easing of the mobility restrictions during the period of time related to Christmas and the end of 2020 led to an increase in new cases of COVID-19, corresponding to the beginning of a third wave that overlaps with the final part of the second wave.

\section{Materials and Methods}

\subsection{Events}

During the COVID-19 pandemic in Portugal, the government adopted several measures to mitigate the spread of the disease. The main measures are grouped in Table 1. In November 2020, a control plan was adopted in Portugal by municipalities [1]. Professionals in epidemiology and public health joined forces to define the criteria for identifying municipalities with the most significant contagion risk.

Table 1. Main public policies to mitigate the spread of COVID-19 in Portugal [1,9-11].

\begin{tabular}{|c|c|c|}
\hline Intervention & Description & Date \\
\hline Public events & $\begin{array}{l}\text { Gatherings with more than } 100 \text { people are } \\
\text { forbidden. }\end{array}$ & 12 March 2020 \\
\hline Physical distancing & $\begin{array}{l}\text { Capacity restrictions in bars and restaurants, } \\
\text { closed night clubs, limiting people in closed } \\
\text { spaces are recommended. }\end{array}$ & 12 March 2020 \\
\hline Schools and universities & Schools and universities closed. & 14 March 2020 \\
\hline Physical distancing & $\begin{array}{l}\text { Decrease in capacity to } 1 / 3 \text { and maintain a } \\
\text { minimum distance of } 1 \mathrm{~m} \text { (ideally } 2 \mathrm{~m} \text { ) in } \\
\text { public services. }\end{array}$ & 17 March 2020 \\
\hline $\begin{array}{l}\text { Self-isolating of ill peo- } \\
\text { ple }\end{array}$ & $\begin{array}{l}\text { Isolation is mandatory for sick people or be- } \\
\text { ing monitored by health authorities. }\end{array}$ & 19 March 2020 \\
\hline First lockdown starts & Start of the first lockdown. & 22 March 2020 \\
\hline Public gatherings & $\begin{array}{l}\text { Gatherings of more than five people prohib- } \\
\text { ited, except for large families. }\end{array}$ & 2 April 2020 \\
\hline First lockdown end & End of the first lockdown. & 3 May 2020 \\
\hline Use of masks & Mandatory masks in all spaces. & 28 October 2020 \\
\hline $\begin{array}{l}\text { Adoption of risk levels } \\
\text { at national level }\end{array}$ & $\begin{array}{l}\text { Municipalities of Portugal classified by levels } \\
\text { of contagion risk by COVID-19. }\end{array}$ & $\begin{array}{l}11 \text { November } \\
2020\end{array}$ \\
\hline Start of vaccination & First vaccine applied in Portugal. & 27 December 2020 \\
\hline Second lockdown start & Start of the second lockdown. & 15 January 2021 \\
\hline Tightening of measures & $\begin{array}{c}\text { Increased policing and punishments for } \\
\text { breaking rules. }\end{array}$ & 22 January 2021 \\
\hline Schools and universities & Schools and universities closed. & 22 January 2021 \\
\hline
\end{tabular}

The government adopted a measure of the cumulative incidence level at 14 days, which corresponds to the number of new cases in the last 14 days per 100,000 inhabitants. The metric is similar to that adopted in Europe [12]. Municipalities with more than 240 
cases per 100,000 inhabitants are included in the risk list, with special restrictive measures. More details for each risk level can be seen in Table 2 .

Table 2. Measures based on the risk of contagion by COVID-19 [1].

\begin{tabular}{ccc}
\hline Classification & Threshold & Measures \\
\hline Moderate & cases/100,000 Inhabitants $<240$. & \\
High & $240 \leq$ cases $/ 100,000$ Inhabitants $<480$. & 1 \\
Very high & $480 \leq$ cases $/ 100,000$ Inhabitants $<960$. & $1,2,3$ \\
Extremely high & cases/100,000 Inhabitants $\geq 960$. & $1,2,3,4$ \\
\hline
\end{tabular}

1. Curfew between $11 \mathrm{pm}$ and 5 am every day; 2 . Curfew between $1 \mathrm{pm}$ and 5 am on Saturday and Sunday. 3. Curfew on the holidays of December 1 and $8 ; 4$. Closing of stores at 3 pm on 30 November and 7 December.

In addition, measures for suspension of face to face teaching, mandatory use of masks in the workplace, teleworking, the prohibition of travel between municipalities, closure of shops at $10 \mathrm{pm}$, and restaurants and cultural facilities at 10:30 pm were defined nationally. During Christmas, restrictive measures were relaxed, travel was allowed, restaurants could stay open until $1 \mathrm{am}$, and there was no limit to the number of people in gatherings. The result was that in January, the number of infections skyrocketed and so a second lockdown was enforced on 15 January 2021. There was no significant decrease in mobility in the first few days, so more severe measures were adopted on January 22, 2021, with schools being closed and the tightening of the policing and punishments for non-compliance with the rules.

\subsection{Data}

The data supporting this study was based on mobility patterns, cases of COVID-19, and the number of vaccines administered. This study used data from three main sources:

- Mobility data is based on the Google COVID-19 Community Mobility Reports [12];

- Daily cases of COVID-19 are from Roser et al. [13];

- Vaccines and tests performed are from Data Science for Social Good Portugal [9].

The mobility report consists of data collected from mobile devices to quantify people's movements during the pandemic. These values are anonymous and aggregated based on Google's algorithm. Also, an artificial noise sample is added to ensure that no individual can be identified based on their location information. More details on the data processing and anonymization process can be seen in [13]. The information present in this report is grouped into six categories, as shown in Table 3.

Table 3. Mobility report categories $[9,14]$.

\begin{tabular}{cc}
\hline Category & Subcategories \\
\hline Retail and recreation & $\begin{array}{r}\text { Restaurants, cafes, shopping centers, theme parks, museums, li- } \\
\text { braries, and movie theaters. }\end{array}$ \\
Grocery and pharmacy & $\begin{array}{r}\text { Grocery markets, food warehouses, farmers markets, specialty } \\
\text { food shops, drug stores, and pharmacies. }\end{array}$ \\
Parks & $\begin{array}{c}\text { National parks, public beaches, marinas, dog parks, plazas, and } \\
\text { public gardens. }\end{array}$ \\
Transit stations & Public transport hubs such as subway, bus, and train stations. \\
Workplaces & Places of work. \\
Residential & Places of residence. \\
\hline
\end{tabular}

The values presented for these categories are related to a baseline, which corresponds to 3 January and 6 February 2020 [14]. In Figure 1, these values represent the Portuguese public's adhesion to the isolation measures during the first year of the pandemic. Values close to zero are considered normal for the baseline; higher values show increased concentration of people in these areas. Values below zero mean decreasing concentration of 
people in these areas. The other figure used to understand the evolution of the pandemic is the number of daily cases detected in Portugal (Figure 2).

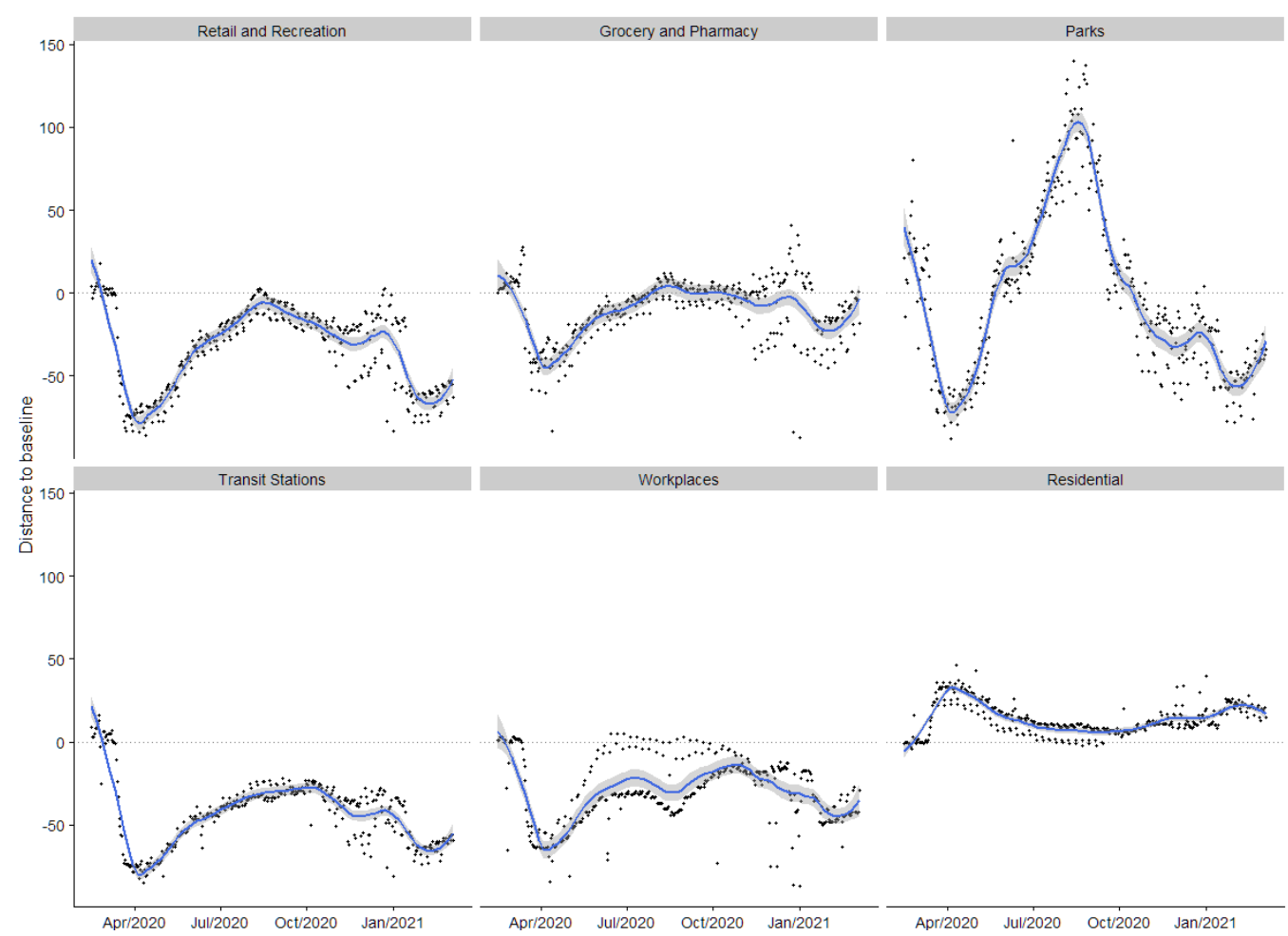

Figure 1. Mobility patterns for Portugal (from 2020-02-02 to 2021-03-06).

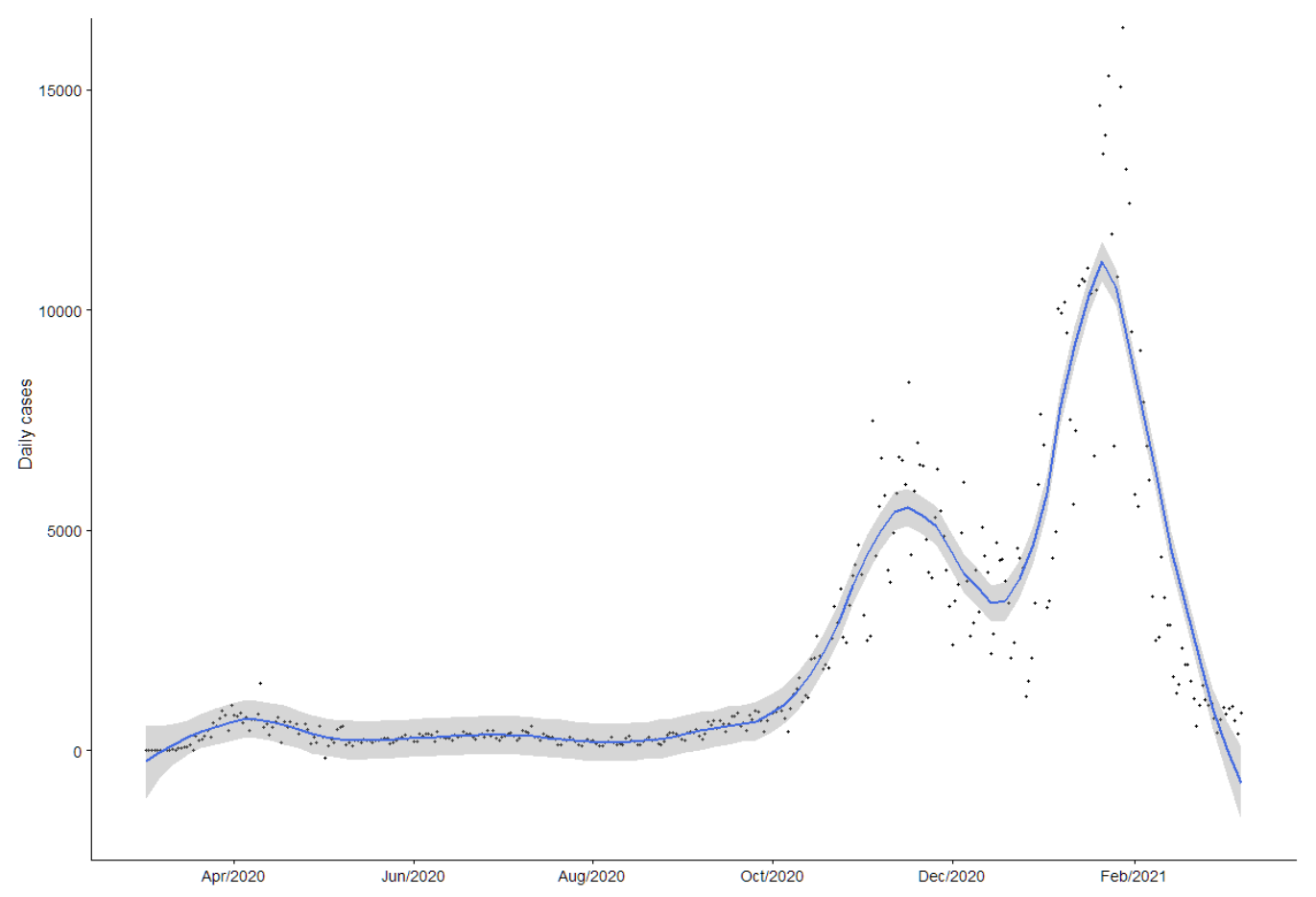

Figure 2. Cases COVID-19 Portugal (from 2020-03-02 to 2021-03-09)

In all images used in this study, the ticker represents the first day of the month to facilitate graphic representation. In this graph, it is possible to identify the three waves in Portugal. The first was between March and May 2020. The second wave was between October 2020 and December 2020. The third wave, graphically overlapping the second wave, initiated at the beginning of 2021. These data are essential to understand the pandemic. 
However, they must correspond only to the detected cases. Studies indicate that a considerable percentage of the infected people are asymptomatic and difficult to detect [15-18].

Measures such as physical distance, hand washing, and even the lockdown were essential to slow down the spread in the community, but appear not to be a definitive solution for Portugal. The best option would be to achieve herd immunity. Then, vaccination against COVID-19 in Portugal started on 27 December 2020 [8]. Figure 3 shows the vaccination phase in Portugal on 9 March 2021. On 9 March 2021, 7,34\% of the Portuguese population had received at least one dose of the vaccine against COVID-19, and 2.90\% had already received two doses. The Portuguese population is just over 10 million, and the vaccines administered so far require two doses. Therefore, considering a vaccination rate of 14,470 vaccines applied per day (average value), it would take 2 years and 6 months from now to immunize $70 \%$ of the population. If the calculation is done based on the average of vaccines applied in the last 14 days, that period would change to 1 year and 5 months. Thus, the goal of vaccinating $70 \%$ of the population is still far away.

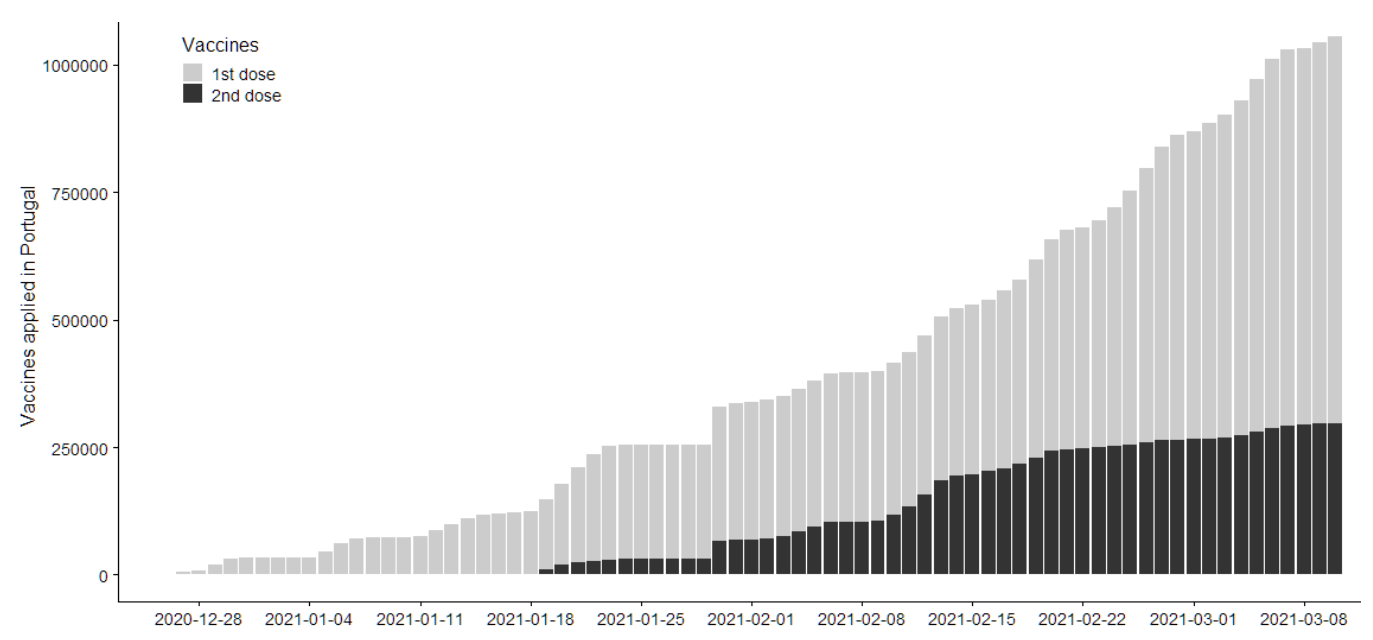

Figure 3. Vaccines against COVID-19 administered in Portugal (from 2020-12-27 to 2021-03-09)

\subsection{Methods}

As mentioned before, this study used data from various sources. To generate value for the study the data needed to be prepared. Thus, the workflow used for data pre-processing can be seen in Figure 4.

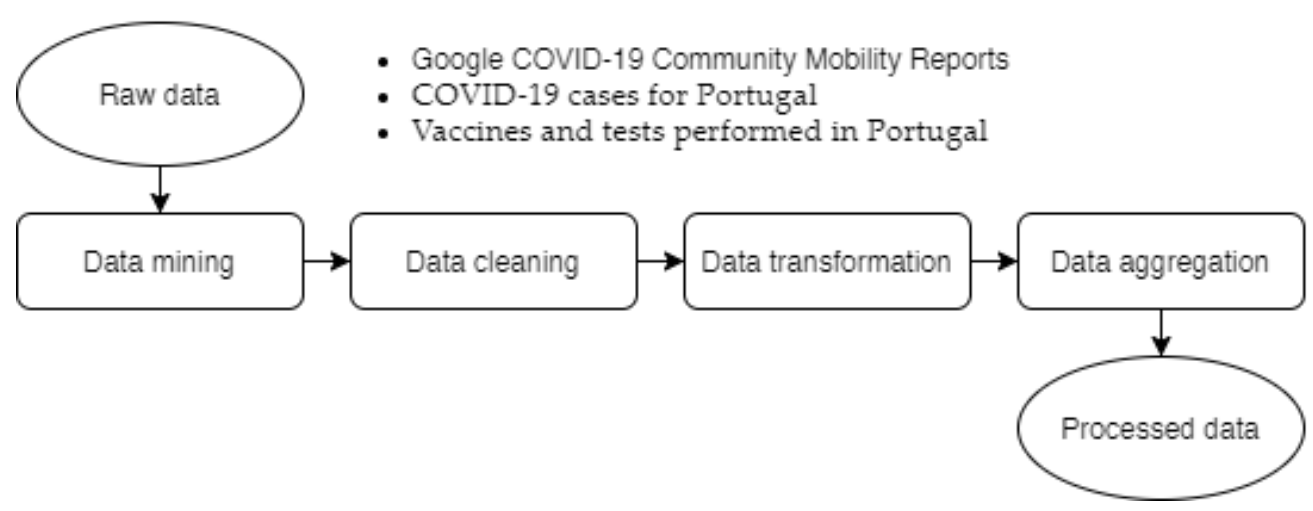

Figure 4. Pre-processing workflow.

The data is collected in its raw form, cleaned, transformed, and finally aggregated. This entire process is done using the R programming language $[19,20]$, and the codes are available in the supplementary material.

The main idea of this study is that the spread of COVID-19 can be limited by decreasing the contact between infected and susceptible individuals. This decline in contact is a challenging measure for the government to implement and often encounters privacy 
issues. Therefore, aggregated location data were used in this study. These values are anonymous and represent a portion of the population. Thus, it is considered that if the population decreases its presence in parks, restaurants, transport hubs, among others, the number of risk contacts will drop [9].

The statistical methods, calculations, and graphs were developed with $\mathrm{R}$ programming language $[19,20]$ support. To calculate the value of $R t$ in Portugal, the EpiEstim framework was used [21]. As mentioned, $R t$ is the average number of secondary cases that each infected individual would infect if conditions remained as they were at time $t[3,4]$. Thus, the value of $R t$ can be determined according to Equation (1) [21].

$$
R(t)=\sum_{s=1}^{t} I_{t-s} w s,
$$

where $I$ is the number of people infected at any given time, and ws corresponds to the probability of infection distribution. To determine the $w s$, the method adopted was nonparametric serial interval (SI). The model parameters used were $\mu=4.6$ days (median serial interval) and $\sigma=2.9$ days (standard deviation) [22]. This means that the average time for infected people to generate a second infection is 4.6 days. However, as COVID-19 varies for each infected individual, a serial interval is used to consider this infectious period. Consequently, an infected individual's infectious window can last up to 14 days [23]. Then, it is used to identify the spread of an infectious disease in a given population. For example, an Rt of 3 means that each infected person, on average, transmits the disease to three other people. On the other hand, an Rt of less than 1 indicates that the spread tends to decrease over time, as each infected person transmits the disease to less than one person $[3,4]$. This is an important indicator and has been widely used during the COVID-19 pandemic. The objective is to keep this value as low as possible, with values less than 1 as an ideal value.

The changepoint framework [24] was also used to detect changing mobility values over time. Using this framework, it was possible to determine (approximately) the day when the mobility values trend changed. The Binary Segmentation (BINSEG) method $[24,25]$ was used to find the changepoints in mobility patterns in the six categories mentioned above. The binary segmentation method consists of calculating a single changepoint, dividing it into two subsets of data. Then the point of change is recalculated again for each subset $[25,26]$. This process is repeated until the model parameters are satisfied. In this study, the framework was used as a parameter to search no more than three points of change in the sample under analysis.

\section{Results}

The collected data were processed and generated the Rt value in Portugal and the changepoints for the mobility categories as outputs. The result of the Rt, based on epidemiological modeling developed for the COVID-19 pandemic in Portugal, is shown in Figure 5. Also, the complete result of the epidemiological modeling is presented in Appendix A. As the framework uses the first seven days for the calculation and the first case of COVID-19 in Portugal was on 3 March 2020, the results for $R t$ are from 10 March 2020 through 9 March 2021. According to [9], at the beginning of the pandemic, transmission occurred exponentially, with $R t$ greater than 3 . With the rapid response of the Portuguese government, this value quickly dropped to less than 1 . However, the transmissibility of COVID-19 in Portugal has rarely decreased from 1. In December 2020, there was a downward trend, leading up to the Christmas and New Year festivities. Many people were tested before Christmas (Figure 6). Only a small number of cases were found resulting from these tests. Nevertheless, there was an explosion of contagions at the beginning of 2021. The strategy of increasing the number of tests seems to have been ineffective in preventing the spread of the virus at the end of the year. The result was a rapid turnaround in the trend, which lasted until strict measures were adopted in the middle of January 2021. After this second lockdown, cases are rapidly decreasing. Nonetheless, the downward trend in February is already being reversed in March, so it is necessary to resist the 
idea of abruptly releasing restrictions. Otherwise, the same situation as that which occurred at the end of 2020 will be repeated.

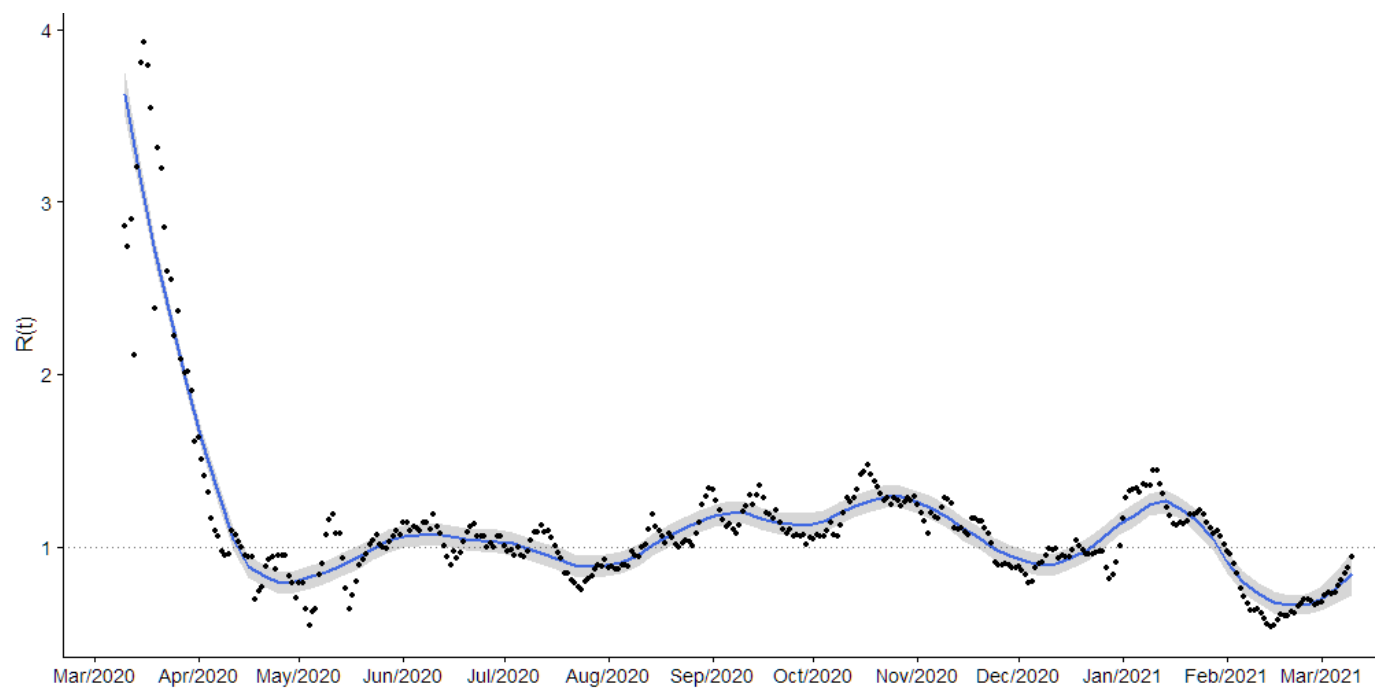

Figure 5. Estimated $R t$ for Portugal (from 2020-03-10 to 2021-03-09).

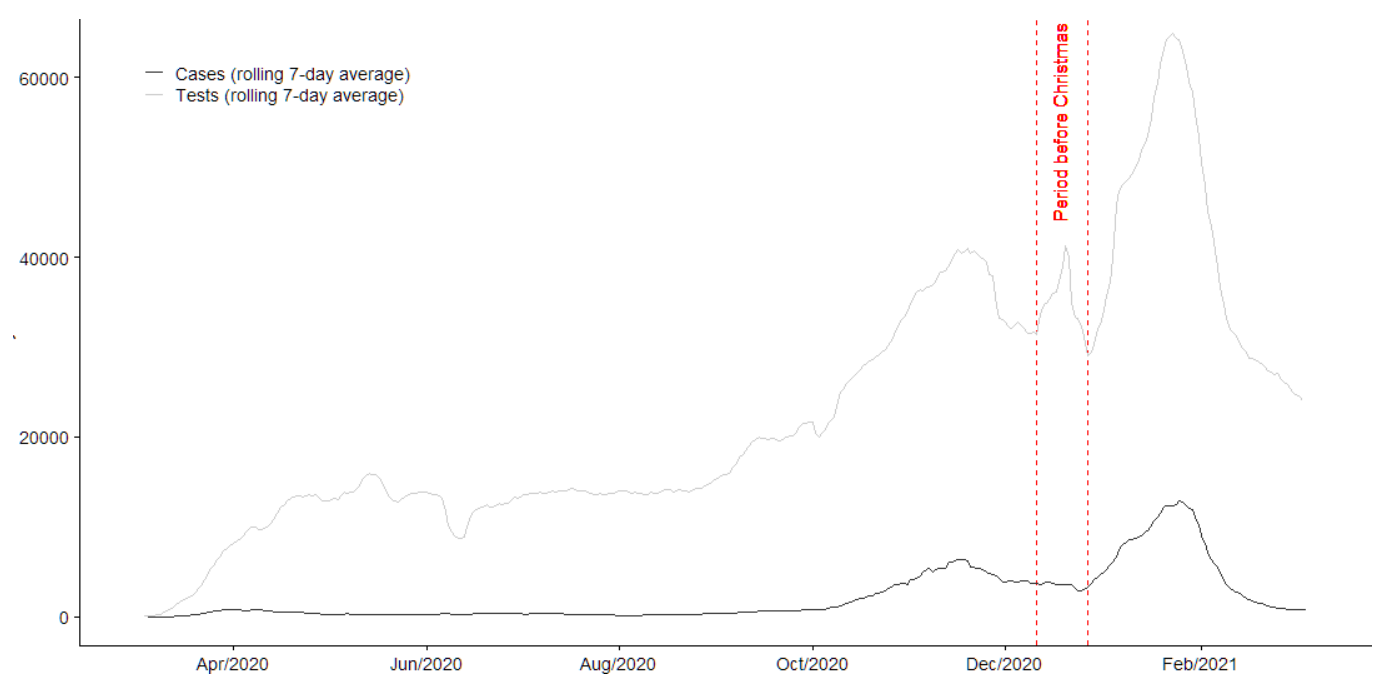

Figure 3. COVID-19 cases and tests in Portugal (from 2020-03-02 to 2021-03-09)

Focusing on mobility data, it was possible to calculate the changepoints in the population's behavior. These changepoints represent shifts in mobility trends and for this study three changepoints were considered. The first three graphs correspond to the retail and recreation, grocery and pharmacy, and parks categories (Figure 6). The following graphs (Figure 7) show the changepoints for the categories transit stations, workplaces, and residential. Analyzing the graphs, at the beginning of the pandemic (March 2020), the mobility pattern for Portuguese population was similar in all categories. There was a sharp drop with the adoption of the first restrictive measures, and people remained at home, with the residential category rising sharply. The changepoints were consistent and the restrictive measures were effective. It is noteworthy that most of the parks were closed in the first lockdown (between 22 March and 3 May). Furthermore, the places with the most significant drops were transit stations, with values above $80 \%$ for the baseline.

After this first impact of the containment measures, the public mobility patterns changed. The retail and recreation category was a portrait of governmental measures, and the variations are correlated to the current restrictive measures. The grocery and pharmacy category had no further sharp falls. The parks peaked during the summer and 
holiday months. An important point, which may have repercussions in the future, is the transit stations, which have had a sharp decline since the beginning of the pandemic. Public transport will have to reinvent itself with ideas that can guarantee the public's safety and maintain an efficient operation.

This year of pandemic has changed the population's relationship with mobility, with telework becoming an alternative for many professions. This new way of working will change the entire transport matrix and how people move $[27,28]$. The post-pandemic mobility of COVID-19 should not be as it was before, and decision-makers should take this into account.
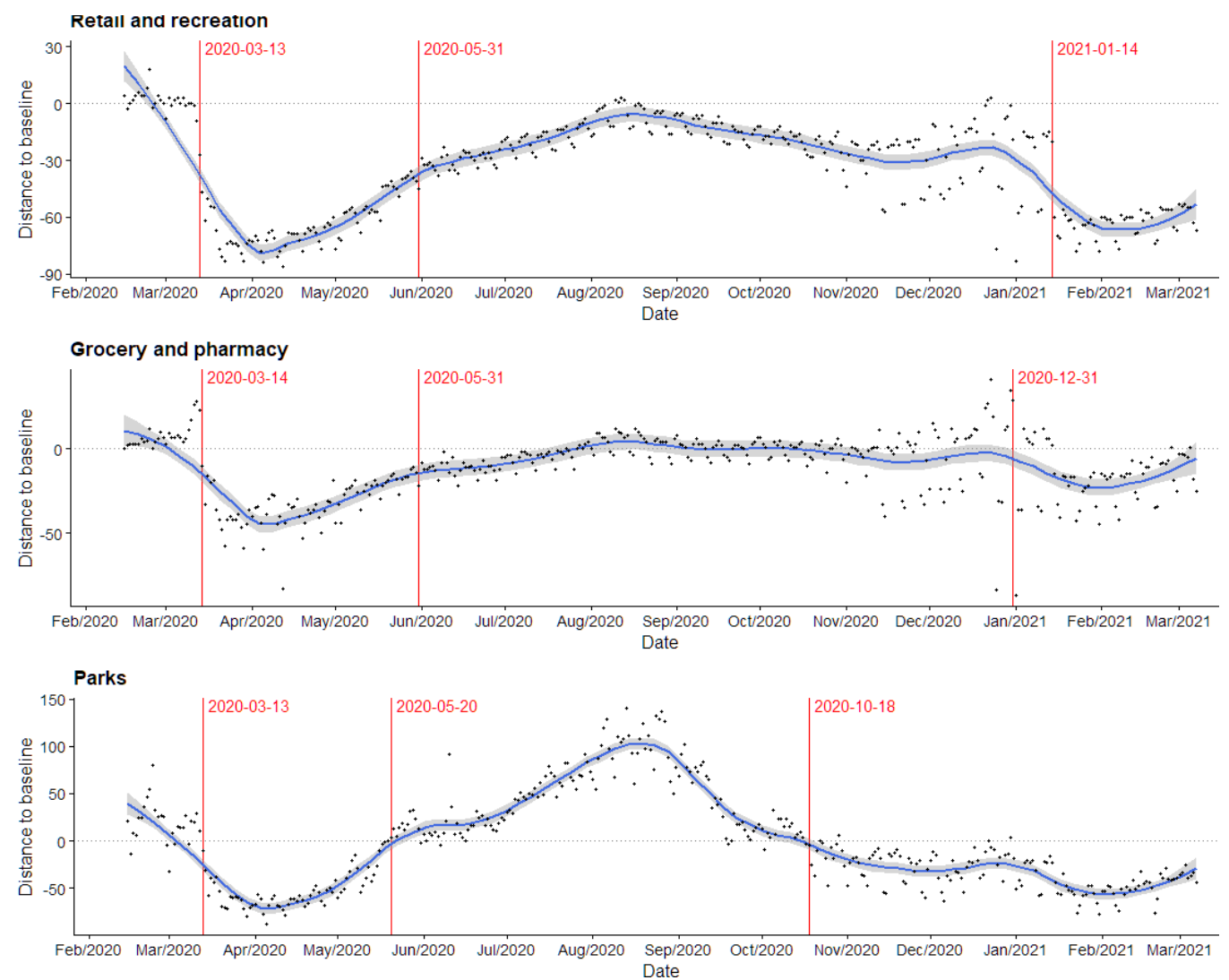

Figure 6. Changepoint for the retail and recreation, grocery and pharmacy, and parks categories in Portugal (from 2020-02-15 to 2021-03-06). 

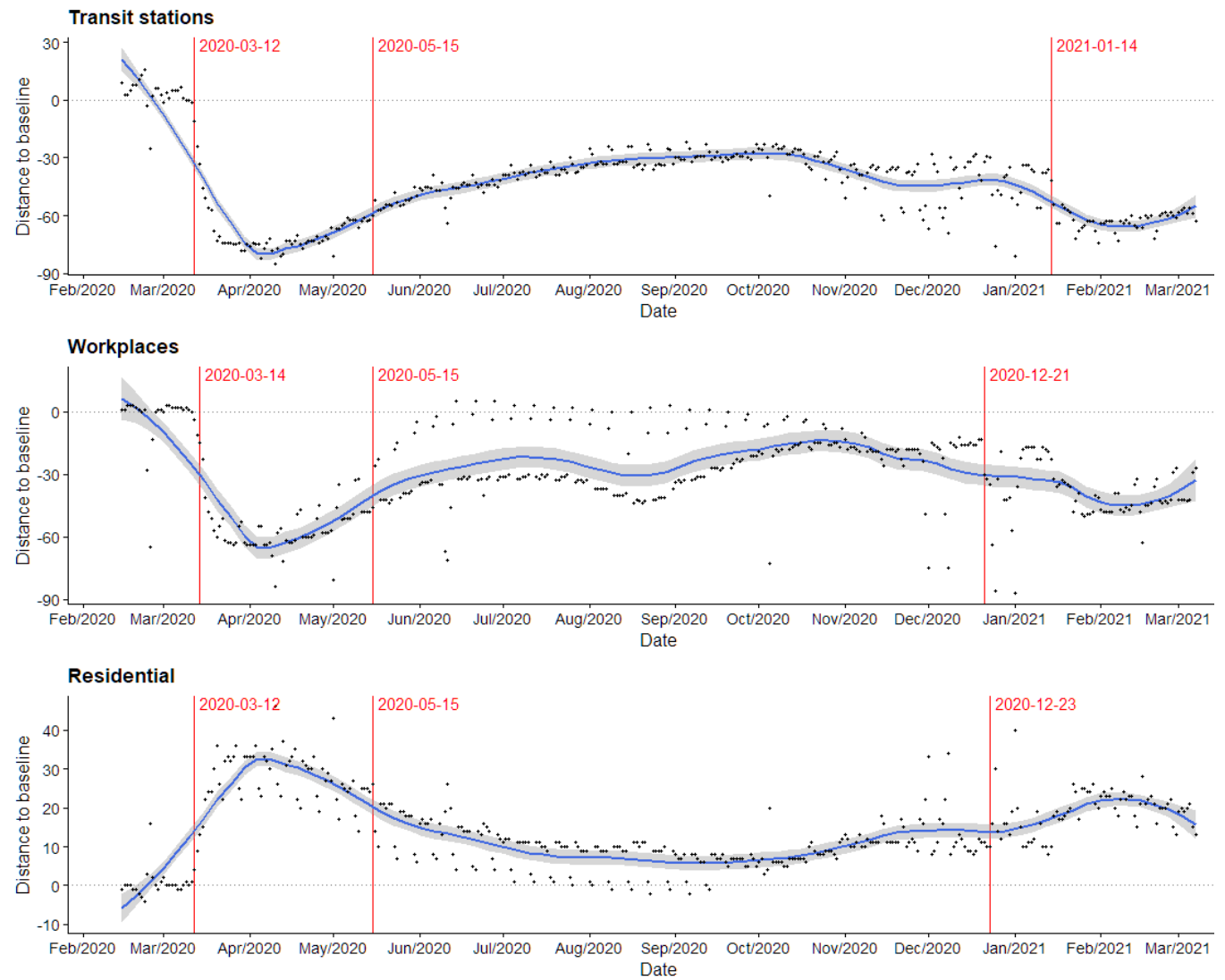

Figure 7. Changepoint for the transit stations, workplaces, and residential categories in Portugal (from 2020-02-15 to 2021-03-06).

\section{Discussion}

There was an apparent slowdown of the covid-19 pandemic in Portugal last month. The $R t$ value is currently below the threshold of 1 , but it is growing slightly. If this trend continues, this phase of declining cases may soon reverse. On the other hand, it is necessary to resume business activities without losing all the progress achieved. On March 15, 2021, a relaxation plan for restrictive measures was initiated. This planning will be more cautious than the previous ones and will take a month and a half. This plan has two thresholds: $R t$ value less than 1 , and the number of 120 cases per 100 thousand inhabitants. If either of these two values is exceeded, the plan will be reevaluated, and further restrictive measures may be adopted [1].

Analyzing the fight against COVID-19 for a year in Portugal shows the public follow the rules when there are restrictive measures. However, when restrictions are eased, there has been a tendency to exaggerate the increase in mobility, and contacts are quickly resumed. Thus, Rt tends to rise. This factor has led to the exhaustion of Portuguese society in general. Observing the pandemic phases in Portugal, the adoption of restrictive measures to ensure a low number of infected people was essential in the first wave [7]. Nevertheless, the speed of taking measures was not so evident in the subsequent waves.

Currently, there are new variables in the equation, which are the possibility of immunizing a portion of the population and the appearance of new variants. Vaccination started on December 27, 2020, but the vaccination rate is not as high as expected in Portugal, with only $2.90 \%$ of the population being fully immunized (two doses) and only $7.34 \%$ receiving at least one dose.

Regarding the mobility patterns of the Portuguese population during the pandemic, there has been a change over the various phases. There was linear confinement at first, with the population avoiding all sorts of places and staying at home. After that period, when the virus was unknown, it was understood that parks and green areas were lowrisk areas and provide physical and mental well-being during the lockdown [29-32]. 
Among the six categories used as a mobility proxy, those which maintained a stricter relationship with the government's restrictive measures were retail and recreation and transit stations. Finally, during this pandemic, the relationship between work and workplaces changed. This is clear when we look at the mobility patterns for the residential and workplace categories. Even when restrictive measures were lifted, these locations did not return to the reference values.

\section{Recommendations}

The first recommendation is to accelerate the production of vaccines already approved by the European Medicines Agency (EMA) and other international drug agencies to vaccinate about $70 \%$ of the population so we will have herd immunity. All pharmaceutical companies must sign agreements to produce vaccines under license from the company that holds the international patent. The European Commission should promote profit-sharing agreements with the production and sale of approved vaccines.

The public transport system needs to be improved to allow the users' physical distancing during the COVID-19 pandemic. Telecommuting (working from home) must be promoted even as restrictions are eased so that only necessary travel occurs. The hours of starting and finishing work in institutions and companies could be staggered to lower the number of employees traveling at the same time. Active mobility (cycling, walking) must be promoted because it improves the environment (reduces GHG emissions), reduces the necessary number of public transport vehicles, and increases public health. The road space in cities should be reallocated to accommodate active mobility and increase the physical distance between cyclists and pedestrians. The utilization of electric bikes must be promoted to allow more extended trips.

In a pandemic situation like the COVID-19 crisis, there is a rare opportunity to create disruptive actions. In this sense, cities should be reinvented, with more green spaces, more space for pedestrians (ensuring a safe distance), more space for active transport, and less need for extensive commuting. Therefore, one must fight the virus with vaccines, medications, social distancing, masks, hygiene measures, and more human and green cities.

\section{Conclusions}

There is a dichotomy between the need to contain the virus's spread and the desire to reopen the economy. Thus, there is a discourse of hope with the beginning of vaccination. This may be good for the economy, but a fourth wave may occur in Portugal if this opening is too fast. To avoid repeating the mistakes of May and September 2020, the government adopted a phased plan to resume face-to-face activities. The resumption of mobility and contacts between people are expected to increase the spread of COVID-19 again.

Our study shows a correlation between population mobility and the number of COVID-19 cases. Thus, restricting mobility is a way of limiting the spread of the virus. Lockdown is not a popular measure, it is not the first option, and it is not desired. However, it is the medicine that existed at the time, and it proved to be effective. Also, it was observed that there must be clear rules with few exceptions, as mobility has decreased little with the first "softer measures".

Mobility patterns and the population's demands are changing rapidly, and new forms of mobility can be a tool to improve the quality of life in cities. Therefore, policymakers and transport researchers now have an excellent opportunity to work together and design new transport policies for a healthier and more sustainable life.

\section{Limitations}

The main limitation encountered during this study is the lack of open raw data related to the cases of COVID-19 in Portugal. The numbers used in this study are values processed from the Directorate-General of Health (DGS) and, in this sense, we must thank Data Science for Social Good Portugal for realizing this task. Another critical point is that the $R t$ value was obtained based on the number of infected people confirmed daily. These numbers may not correspond to the reality of the disease, as the number of confirmed 
infections depends on the number of tests performed [33] and the ability to track existing cases. The values reported by the DGS do not indicate the day of infection or when the case was detected. They tell us only which day the data were computed in the system. Therefore, it is expected that there will be some mismatch between detection and notification and also underreporting of cases.

Supplementary Materials: The code developed in $\mathrm{R}$ can be accessed at the repository github.com/tamagusko/mobility_portugal_first_year_covid19.

Author Contributions: Conceptualization, A.F. and T.T.; methodology, A.F. and T.T.; software, T.T.; validation, A.F. and T.T.; formal analysis, A.F.; investigation, A.F. and T.T.; resources, A.F. and T.T.; data curation, T.T.; writing - original draft preparation, A.F and T.T.; writing - review and editing, A.F.; visualization, T.T.; supervision, A.F.; project administration, A.F.; funding acquisition, A.F. All authors have read and agreed to the published version of the manuscript.

Funding: This research was funded by the Research Center for Territory, Transports and Environment (CITTA), and also by ACIV.

Data Availability Statement: The data that support the results presented can be accessed in the repository github.com/tamaguskomobility_portugal_first_year_covid19/data.

Conflicts of Interest: The funders had no role in the study; in the collection, analyses, or interpretation of data; in the writing of the manuscript, or in the decision to publish the results.

\section{Appendix A}

The result of the epidemiological modeling (Figure A1).
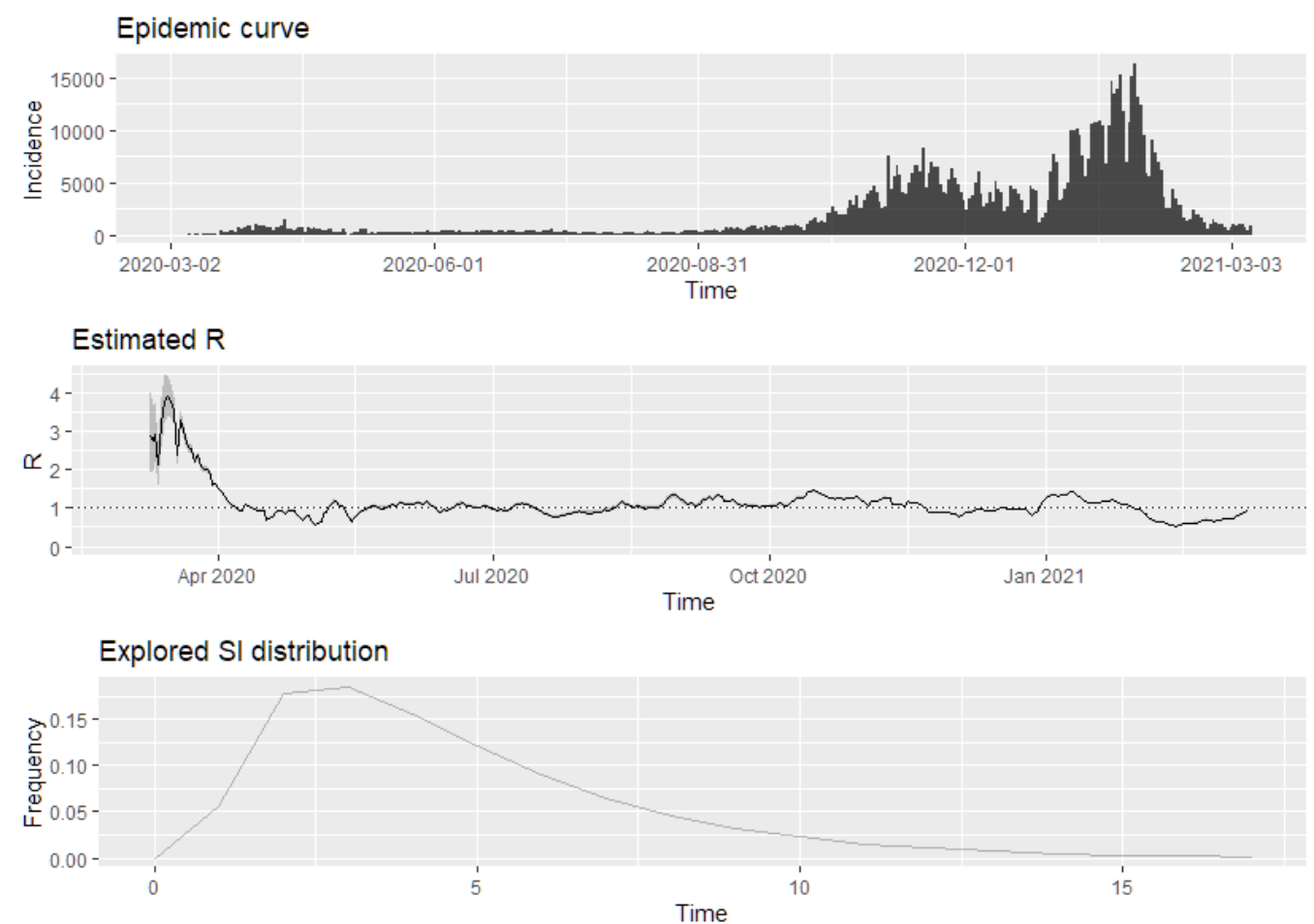

Figure A1. Result of epidemiological modeling (from 2020-02-15 to 2021-03-09).

\section{References}

1. Portugal Estamos On: Resposta de Portugal à COVID-19. Available online: https://covid19estamoson.gov.pt (accessed on Mar 10, 2021).

2. World Health Organization Coronavirus disease (COVID-19)

3. Haydon, D.T.; Chase-Topping, M.; Shaw, D.J; Matthews, L.; Friar, J.K.; Wilesmith, J.; Woolhouse, M.E.J. The construction 
and analysis of epidemic trees with reference to the 2001 UK foot-and-mouth outbreak. Proc. R. Soc. B Biol. Sci. 2003, 270, 121127, doi:10.1098/rspb.2002.2191.

4. Wallinga, J.; Teunis, P. Different epidemic curves for severe acute respiratory syndrome reveal similar impacts of control measures. Am. J. Epidemiol. 2004, 160, 509-516, doi:10.1093/aje/kwh255.

5. Neil M, F.; Daniel, L.; Gemma, N.-G.; Natsuko, I.; Ainslie, K.; Marc, B.; Sangeeta, B.; Adhiratha, B.; Zulma, C.; Gina, C.-D.; et al. Impact of non-pharmaceutical interventions (NPIs) to reduce COVID-19 mortality and healthcare demand. Imp. Coll. COVID-19 Response Team 2020, doi:https://doi.org/10.25561/77482.

6. Hsieh, C.C.; Lin, C.H.; Wang, W.Y.C.; Pauleen, D.J.; Chen, J.V. The outcome and implications of public precautionary measures in taiwan-declining respiratory disease cases in the COVID-19 pandemic. Int. J. Environ. Res. Public Health 2020, 17, 1-10, doi:10.3390/ijerph17134877.

7. Moreira, A.; Léon, M.; Coda Moscarola, F.; Roumpakis, A. In the eye of the storm... again! Social policy responses to COVID19 in Southern Europe. Soc. Policy Adm. 2020, 1-19, doi:10.1111/spol.12681.

8. Data Science For Social Good Portugal. Data on the COVID-19 pandemic in Portugal Available online: https://github.com/dssg-pt/covid19pt-data (accessed on Mar 10, 2021).

9. Tamagusko, T.; Ferreira, A. Data-Driven Approach to Understand the Mobility Patterns of the Portuguese Population during the COVID-19 Pandemic. Sustainability 2020, 12, 9775, doi:10.3390/su12229775.

10. Portugal Governo da República Portuguesa. Available online: https://www.portugal.gov.pt (accessed on Mar 10, 2021).

11. ECDC Situation updates on COVID-19 Available online: https://www.ecdc.europa.eu/en/publications-data/download-dataresponse-measures-covid-19 (accessed on Feb 18, 2021).

12. Peralta-Santos, A.; Nunes, B.; Gomes, B.M.; Nunes, C.; Antunes, C.; Gouveia, J.; Gomes, M.C.; Felgueiras, Ó. Linhas vermelhas I Epidemia de Infeção por SARS-COV-2/COVID-19; 2021;

13. Aktay, A.; Bavadekar, S.; Cossoul, G.; Davis, J.; Desfontaines, D.; Fabrikant, A.; Gabrilovich, E.; Gadepalli, K.; Gipson, B.; Guevara, M.; et al. Google COVID-19 Community Mobility Reports: Anonymization Process Description (version 1.0). 2020, $1-5$.

14. Google LLC. Google COVID-19 Community Mobility Reports. Available online: https://www.google.com/covid19/mobility/ (accessed on Mar 10, 2021).

15. Mizumoto, K.; Kagaya, K.; Zarebski, A.; Chowell, G. Estimating the asymptomatic proportion of coronavirus disease 2019 (COVID-19) cases on board the Diamond Princess cruise ship, Yokohama, Japan, 2020. Eurosurveillance 2020, 25, 1-5, doi:10.2807/1560-7917.ES.2020.25.10.2000180.

16. Gandhi, M.; Yokoe, D.S.; Havlir, D. V. Asymptomatic Transmission, the 'Achilles' Heel of Current Strategies to Control COVID-19. COVID-19 Read. 2020, 36-39, doi:10.4324/9781003141402-4.

17. Nishiura, H.; Kobayashi, T.; Miyama, T.; Suzuki, A.; Jung, S. mok; Hayashi, K.; Kinoshita, R.; Yang, Y.; Yuan, B.; Akhmetzhanov, A.R.; et al. Estimation of the asymptomatic ratio of novel coronavirus infections (COVID-19). Int. J. Infect. Dis. 2020, 94, 154-155, doi:10.1016/j.ijid.2020.03.020.

18. Li, Q.; Guan, X.; Wu, P.; Wang, X.; Zhou, L.; Tong, Y.; Ren, R.; Leung, K.S.M.; Lau, E.H.Y.; Wong, J.Y.; et al. Early Transmission Dynamics in Wuhan, China, of Novel Coronavirus-Infected Pneumonia. N. Engl. J. Med. 2020, 382, 1199-1207, doi:10.1056/nejmoa2001316.

19. RStudio Team. RStudio: Integrated Development for R 2020.

20. R Core Team. R: A language and environment for statistical computing. R Foundation for Statistical Computing 2017.

21. Cori, A.; Ferguson, N.M.; Fraser, C.; Cauchemez, S. A new framework and software to estimate time-varying reproduction numbers during epidemics. Am. J. Epidemiol. 2013, 178, 1505-1512, doi:10.1093/aje/kwt133.

22. Nishiura, H.; Linton, N.M.; Akhmetzhanov, A.R. Serial interval of novel coronavirus (COVID-19) infections. Int. J. Infect. Dis. 2020, 93, 284-286, doi:10.1016/j.ijid.2020.02.060.

23. WHO Considerations for quarantine of individuals in the context of containment for coronavirus disease ( COVID-19). Who 
2020, 3-5.

24. Killick, R.; Eckley, I.A. changepoint: An R Package for Changepoint Analysis. J. Stat. Softw. $2014,58$.

25. Scott, A.A.J.; Knott, M. A Cluster Analysis Method for Grouping Means in the Analysis of Variance Published by: International Biometric Society Stable URL : http://www.jstor.org/stable/2529204. Biometrics 1974, 30, 507-512.

26. Killick, R.; Fearnhead, P.; Eckley, I.A. Optimal detection of changepoints with a linear computational cost. J. Am. Stat. Assoc. 2012, 107, 1590-1598, doi:10.1080/01621459.2012.737745.

27. Gonz, G.; Olmo-s, I.; Maeso-gonz, E. Challenges and Strategies for Post-COVID-19 Gender Equity and Sustainable Mobility. 2021.

28. Zhang, J.; Hayashi, Y. Impacts of COVID 19 on the transport sector and measures as well as recommendations of policies and future research: Analyses based on a world wide expert survey; 2020;

29. Slater, S.J.; Christiana, R.W.; Gustat, J. Recommendations for keeping parks and green space accessible for mental and physical health during COVID-19 and other pandemics. Prev. Chronic Dis. 2020, 17, 1-5, doi:10.5888/PCD17.200204.

30. Venter, Z.S.; Barton, D.N.; Gundersen, V.; Figari, H.; Nowell, M. Urban nature in a time of crisis: recreational use of green space increases during the COVID-19 outbreak in Oslo, Norway. Environ. Res. Lett. 2020, 15, 104075, doi:10.1088/17489326/abb396.

31. Twohig-Bennett, C.; Jones, A. The health benefits of the great outdoors: A systematic review and meta-analysis of greenspace exposure and health outcomes. Environ. Res. 2018, 166, 628-637, doi:10.1016/j.envres.2018.06.030.

32. Heo, S.; Lim, C.C.; Bell, M.L. Relationships between local green space and human mobility patterns during COVID-19 for Maryland and California, USA. Sustain. 2020, 12, 1-16, doi:10.3390/su12229401.

33. Gopalan, A.; Tyagi, H. How Reliable are Test Numbers for Revealing the COVID-19 Ground Truth and Applying Interventions? J. Indian Inst. Sci. 2020, xxx, 1-22, doi:10.1007/s41745-020-00210-4. 